\title{
Estudo comparativo da oralidade civil e da oralidade penal
}

\author{
Joaquim Canuto Mendes de Almeida
}

\section{A oralidade no Código de Processo Civil}

1. A "exposição de motivos", vestibular ao Código de Processo Civil, subscrita pelo ministro da Justiça, põe em fóco, nos incisos $8 .^{\circ}, 9 .^{\circ}$ e $10 .^{\circ}(a, b$ e $c)$, a noção de oralidiade:

a) a oralidade, segundo os assertos contidos no inciso 8., torna "mais adequada e eficiente a formação da prova, colocando o juiz em relação a esta na mesma situação em que, deve colocar-se qualquer observador que tenha por objeto conhecer os fatos e formular sobre eles apreciações adequadas ou justas".

O ponto é importante. No processo em vigor - diz o ministro - o juiz só entra em contacto com a prova testemunhal ou pericial através do escrito a que foi reduzida. Não ouviu as testemunhas, não inspecionou as coisas e os lugares.

Qual o valor que conferirá ao depoimento das testemunhas e das partes se não as viu e ouviu, se não seguiu os movimentos de fisionomia que acompanham e sublinham as palavras, se no escrito não encontra a atmosfera que envolvia no momento o autor do depoimento, as suas palavras ou o seu discurso?

Que juizo formará sobre a situação dos lugares e a condição das coisas, descritas no laudo pericial, se de um e de outra não tem nenhuma impressão pessoal? 
Tudo quanto foi objeto de prova, visto apenas através da transcrição de impressões alheias, o juiz o colocará no mesmo plano, por lhe faltar precisamente o critério pessoal, único que o autoriza a medir o valor das provas, a graduar o seu peso, a conferir a cada uma o seu coeficiente específico na formação do juizo.

0 processo oral coloca à disposição do processo judiciário exatamente o método que torna possivel ao espírito humano a aquisição de certezas mais ou menos satisfatórias nos domínios até então entregues ao jogo e ás preferências da opinião."

b) "O principio da concentração dos atos do processo é um dos postulados do sistema oral. No processo tradicional - reza o inciso $90^{\circ}$ — os atos do processo se vão desenvolvendo no tempo à medida da iniciativa das partes. 0 processo tradicional é essencialmente dispersivo e caótico. Quando os atos do processo chegam ao conhecimento do juiz, já medeia um largo tempo entre o momento em que foram praticados e o em que o juiz vai apreciá-los. $O$ princípio da concentração imediatiza o contacto do juiz com o processo e exige que todos os atos e incidentes ocorridos na mesma audiência sejam objeto de solução imediata por parte do juiz. As atividades processuais desenvolvem-se em uma ou mais audiências e, no último caso, em audiências tão próximas quanto possivel umas das outras, de maneira que a decisão sobrevenha quando ainda não se apagaram no espírito do juiz as impressões e o interesse que lhe haja despertado o curso do processo.

O princípio de concentração completa, ainda, a indispensavel situação do juiz relativamente à prova, tornando a formação desta mais favoravel a uma justa e adequada apreciação por parte do juiz".

c) "O princípio que deve reger a situação do jułz inciso $100^{\circ}$ - em relação à prova e o da concentração dos atos do processo postulam, necessáriamente, o princípio da identidade física do juiz. 
0 juiz que dirige a instrução do processo ha de ser o juiz que decida o litígio. Nem de outra maneira poderia ser, pois, o processo visando a investigação da verdade, somente o juiz que tomou as provas está realmente habilitado a apreciá-las do ponto de vista do seu valor ou da sua eficácia em relação aos pontos debatidos".

"Estes os caracteristicos do processo oral", conclue o ministro.

\section{A oralidade no Código de Processo Criminal}

2. Tais considerações se aplicam, perfeitamente, ao processo criminal que, ha mais de um século, no Brasil, se rege pelo princípio da oralidade.

E que efetivamente autor e réu melhor se entendem na imediação do que à distancia; e melhor entendem o juiz presente do que o juiz ausente.

$\mathrm{E}$ vendo-os, ouvindo-os, sentindo-os litigar, melhor os compreende o juiz do que tendo notícias escritas do conflito.

A ação recíproca, de uma parte a outra parte, ou das partes ao juiz, opera-se com a simplicidade das discussões e exposições verbais rápidas e vivas, em que a contrariedade dos desejos e a oposição imediata das provas, possibilitando prontos revides e soluções, dão aspecto global e concentrado à questão, em todos os seus elementos.

Os contendores, que falam ao adversário ou ao juiz aquilo que querem, despendem menor esfôrço do que os que escrevem ou mandam dizer; também possibilitam imediata e facil compreensão de seus desejos, porque o adversário e o juiz, que ouvem, despendem menor esfôrço, por sua vez, do que os que leem ou recebem notícias.

Quando os interlocutores se defrontam, as explicações reclamadas pelos desejos, ordens e pedidos mal expressos ou mal entendidos, são assim requeridas e dadas em curtos instantes. Complicam-se e exigem novos dispêndios de tempo 
e de trabalho, se a distância que os separa depende, como sempre acontece, de transportes ou documentação.

Devem as partes tambem conhecer de perto os meios de prova, para melhor os compreender e, assim, lhes esgotar o conteudo probatório. A inspeção ocular dos vestígios, ou mesmo dos caracteres sensiveis do fato, e a inquirição oral das testemunhas permitem exame detido das mais variadas notas, comparações de urgência e oportunas, confrontos inadiaveis, acurada pesquisa e interpretação de minúcias e aspetos dos sinais ostentados pela matéria das coisas, reperguntas e careações nos depoimentos e declarações ambíguas ou imperfeitas.

Tais exames, comparações, confrontos, pesquisas, explicações ficam, desde logo, no ato da produção, ao alcance dos três agentes do procedimento: autor, réu, juiz.

Isso poupa as suas energias e as semanas ou meses que teriam de gastar se estivessem, não na imediação, porém afastados do tempo e lugar da produção da prova.

A distância, em suma, dificulta a luta judiciária; $e$ a imediação, ao contrário, beneficia a justiça. Autor, réu e juiz, concentrando as próprias atividades no tempo e no lugar da discussão e do julgamento da causa, melhor servem à economia processual, e, com menor esfôrço e maior garantia, realizam os próprios objetivos.

3. Dissemos que, ha mais de século, as leis de nosso processo criminal são subordinadas ao princípio da oralidade.

Deixemos de parte essas leis antigas, para comentar, de relance, alguns preceitos da moderna lei do juri nacional, decreto lei n. 167 de 5 de janeiro de 1938, fieis ao mesmo princípio.

Cumpridas as formalidades preliminares de verificação da presença das partes e demais pessoas indispensaveis à realização da audiência (na qual se concentra o processo criminal), e de formação e compromisso do consềlho dos jurados, o juiz - segundo o que dispõe o artigo 59 - interrogará o réu e, em seguida, fará seu relatório, deduzido das 
peças escritas do processo, expondo o fato, as provas e as conclusões das partes (art. 60).

Terminado o relatório (aí então se inicia o processo concentrado, o processo oral, que é ef etivamente o processo criminal propriamente dito) "o promotor lerá o libelo e os dispositivos da lei penal em que o réu se achar incurso, e produzirá a acusação, mostrando as provas em que se funda".

"Havendo auxiliar de acusação, este falará depois do promotor, e, sendo o processo promovido pela parte of endida, o promotor falará depois dela, tanto na acusação, como na réplica" ( $\S \S 10^{\circ}$ e $\left.2 .^{\circ}\right)$. Finda a acusação, terá a palavra o defensor, para desenvolver a defesa (art. 62).

Em seguida, serão introduzidas na sala da sessão, cada uma por sua vez, as testemunhas de acusação, que devem depor sôbre os artigos do libelo; inquirindo-as primeiro o juiz, o acusador e o auxiliar de acusação, depois o advogado do réu e, por fim, os jurados que o quiserem (art. 63).

Ouvidas as testemunhas de acusação, as testemunhas do réu serão introduzidas na sala, para depor sôbre os artigos da contrariedade ou os fatos alegados pela defesa, sendo inquiridas sucessivamente pelo juiz, pelo advogado do réu, pelo acusador particular, pelo promotor e pelos jurados que quiserem (art. 64).

Quando duas ou mais testemunhas divergirem sôbre pontos essenciais da causa, o juiz as reperguntará, em face umas das outras, mandando que expliquem a divergencia ou contradição (art. 66).

O acusador poderá replicar e a defesa treplicar, sendo admitida a reinquirição de qualquer das testemunhas já ouvidas em plenário (art. 67).

O prazo para os debates é limitado (art. 68).

Segue-se aos debates a decisão, na sala secreta.

Eis a oralidade realizada no processo criminal.

Na audiência do juri, concentram-se todos os seus atos: alegações (leitura do libelo, contrariedade ou defesa, réplica e tréplica), provas testemunhais, interrogatório do réu e, afinal, a sentença. 


\section{Aplicação do principio no civel}

4. Semelhantes são as regras de funcionamento da audiência de instrução, debates e julgamento civel, prescritas pelo Código de Processo Civil nacional.

"Aberta a audiência, o perito fará um resumo do laudo, podendo o juiz, "ex-officio" ou a requerimento, pedir-lhe esclarecimentos", diz ō artigo 267.

Tambem a audiência do juri, como vimos, se inicia pelo relatório do juiz, acerca da prova existente nos autos. Como ninguem ignora, a principal peça, a que deve dar o juiz sua consideração, é o auto de corpo de delito. Nada impede que, a requerimento das partes ou "ex-officio", o presidente do juri determine o comparecimento pessoal dos respectivos subscritores, para, na qualidade de peritos, prestarem, em audiência, esclarecimentos uteis ou necessários.

Intuitivo parece que, sendo, no juizo civel, juiz de fato o mesmo juiz de direito, deva este se contentar com ouvir o perito, dispensando-se de fazer relatório acerca da prova que o laudo exprime ou acerca das outras provas representadas por escritos ja autuados. Um relatório do juiz, em tais condições, teria por destinatário o próprio relator, o que por si só já demonstra quão absurdo seria exigí-lo.

No juri, explica-se que o juiz faça esse relatório, como antigamente, segundo as leis de juri revogadas, faziam os escrivães do juri, preliminarmente, uma leitura das principais peças dos autos. Essa leitura era meio, como hoje é o relatório, de ser dado aos jurados conhecimento dos elementos probatórios já coligidos.

Prossigamos no exame do Código de Processo Civil.

"Finda a exposição do perito — reza o artigo 268 serão tomados sucessivamente os depoimentos do autor, do réu e das testemunhas".

Aqui, ha traços de semelhança e traços de diversificação entre o que ocorre na audiencia civel e o que se passa na audiência do juri. 
A semelhança está em que se, depois do relatório, o juiz presidente do juri passa ao interrogatório do reu, o juiz da instrução civel, logo após o resumo do laudo, feito pelo perito, toma, além do depoimento do autor, o depoimento do réu.

A dif erença está em que, no crime, não é possivel ainda, no estado de nossas leis, tomar depoimento ao réu, mas apenas submetê-lo ao interrogatório, segundo perguntas sacramentais quasi exclusivamente de defesa, cujas fórmulas, redigidas pelo legislador, são por este indeclinavelmente impostas ao juiz.

A diferença está ainda em que tambem a vítima, em processo criminal, quando chamada a depor em plenário, o faz como testemunha, embora informante, mas nunca como autora, mesmo quando, permitido o depoimento pelo juiz, seja parte acusadora ou auxiliar de acusação.

“Terminada a instrução, o juiz fixará os pontos a que deverá limitar-se o debate oral. Em seguida, será dada a palavra ao procurador do autor e ao do réu e ao órgão do ministério público, sucessivamente, pelo prazo de vinte minutos para cada um, prorrogavel por dez, a critério do juiz" (art. 269).

É, como se vê, o que tambem ocorre na audiência criminal. Convém observar que, nesta, as orações das partes precedem a produção das provas, segundo a atual lei do juri. Tome-se, porém, em conta que, pela revogada lei do juri paulista, a inquirição das testemunhas precedia os debates, tal como determina para a audiência civel o Código de Processo Civil nacional.

\section{A oralidade e a instrução preliminar}

5. A oralidade exige, em suma, tanto no crime, como no civel, sejam os meios de prova produzidos na audiência.

Forçoso é, porém, reconhecer, igualmente nos dois ramos, que, na prática nem sempre se consegue, sem sacrificio da pureza, o ideal da imediação. 
Exceções consagram as leis de processo criminal, como acontece no Código de Processo Civil, as quais se ajustam melhor aos reclamos da justiça do que à aplicação rigorosa do princípio de imediatidade. Não é mesmo dificil reconhecê-las.

Bastante é a análise das espécies de provas, para se compreender como nem tudo o que concerne ao processo de uma causa pode ser feito, consecutivamente ou concomitantemente, na audiência.

A inspeção direta, pelo julgador, dos vestígios probatórios encontraveis em coisas moveis de facil transporte, pode realizar-se em concentração processual, sem obstáculos insuperaveis. A medida, porém, que o transporte se dificulta, as vantagens de economia processual dessa inspeção direta vão desaparecendo, até se anularem na impossibilidade de transporte natural ou artificial, trate-se de objetos pesados, de imóveis ou de livros irremoviveis por lei, ou de distâncias ou caminhos invenciveis. $O$ mesmo se verifica quando, embora de facil transporte, os objetos vistoriados só revelam seus caracteres probatórios através de operações custosamente realizaveis, ou de todo irrealizaveis, na audiência da concentração: o enfêrmo ou o cadaver que devam ser examinados pelo juiz ou pelas partes, o material que deva ser submetido a experiências de laboratório, o escrito que deva ser ampliado fotograficamente ou submetido a processos técnicos complicados requerem atos cuja prática deve sujeitar-se às circunstâncias de tempo e de lugar apropriadas.

As testemunhas geralmente podem ser ouvidas na concentração processual. Ocorre, porém, às vëzes, que se acham na impossibilidade, de fato ou por lei, de se locomoverem.

São, por exemplo, enfermos, militares, certos funcionários públicos, com domicílio ou residência forçada distante do fôro da causa.

A produção da prova testemunhal, nesses casos, se desconcentra relativamente a tais depoimentos; e o mesmo acon- 
tece quando a enfermidade não permite à testemunha espera da data de jurar.

Por isso é que os artigos 90 e 91 do velho Código de Processo Criminal, de 1832, dispunham: "Se o delinquente for julgado em um lugar e tivér em outro alguma testemunha que não possa comparecer, poderá pedir que seja inquirida nesse lugar, citada a parte contrária, ou o promotor para assistir à inquirição". "Se alguma testemunha houver de ausentar-se, ou por sua avançada idade, ou por seu estado valetudinário houver receio que ao tempo da prova já não exista, poderá tambem, citados os mencionados no artigo antecedente, ser inquirida a requerimento da parte interessada, a quem será entregue o depoimento para dele usar, quando e como lhe convier".

Esse dispositivo - digamos de passagem - parece ser a fonte do disposto no artigo 250 do Código de Processo Civil nacional.

\section{Instrução preliminar, no civel}

6. De tudo quanto dissemos, se deduz, em suma, que a inadiabilidade da produção da prova e a intransportabilidade dos meios de prova determinam a antecipação da instrução da causa, parcialmente, tanto em matéria criminal, quanto em matéria civel.

Assim como existe uma instrução criminal preparatória, tambem existe, segundo nosso Código de Processo Civil, por assim dizer, uma instrução civel preliminar.

Deixemos de parte o que concerne à prova pericial, por ser intuitivo que não póde ou não deve ser produzida em audiência civel ou criminal.

Contentemo-nos com assinalar que, assim como a atividade dos peritos do corpo de delito precede a sustentação oral da acusação, ponto de partida da audiência criminal, também a atividade dos peritos, em matéria civel, deve preceder, como realmente manda o Codigo nacional, a realização da audiência de instrução, debates e julgamento. 
Demoremo-nos porém na prova testemunhal, para abordarmos o problema de saber se é permitido a outro juiz, diverso do da causa, colher depoimentos de pessoas, que não possam comparecer no lugar e tempo da audiência.

Exprimamo-nos, de outra maneira: podem ser colhidos depoimentos em instrução preparatória, para que valham por escrito perante o julgador?

Nossa resposta é afirmativa, compreendendo, tambem, o reconhecimento de que são permitidas as inquirições em juizo deprecado, o que entretanto já não mais se permite em materia criminal de competência do juri.

"A falta de alguma das testemunhas - reza o artigo 49 da atual lei do juri - não será motivo para adiamento, salvo se qualquer das partes o requerer, indicando com a necessária antecedência o seu paradeiro certo e declarando não prescindir do depoimento. Proceder-se-à entretanto ao julgamento se a testemunha não tiver sido encontrada no local indicado".

Esse dispositivo, aliado à circunstância da inexistência. da carta precatória para inquirições no juizo deprecado, salva contudo, a justiça criminal do risco de decidir sem consideração a uma prova que, embora existente longinquamente, no país ou no estrangeiro, constitua fundamento para a verdadeira solução do caso criminal.

o julgamento, em suma, não se fará aí sem que, convocada a testemunha, regularmente, por precatória ou rogatória, compareça à audiência da concentração processual, para que deponha em relação de imediatidade com os juizes. E certo que isso redundaria em inominavel abuso de os interessados impedirem a realização das diligências, se não fossem instituidas as cautelas deduziveis do poder inquisitivo do juiz, isto é, aquele poder de negar deferimento ao pedido de prova das partes, quando razoavelmente possa entender que se trata de expediente puramente protelatório.

7. Pois bem. Em respeito ao princípio da oralidade, se outros princípios tambem não devesse o Código de Pro- 
cesso Civil respeitar, deveria este vedar, de modo absoluto, a produção de prova testemunhal perante juiz diverso do da causa e fóra da audiência de instrução, debates e julgamento.

Tomando, porém, em consideração a impossibilidade ou dificuldade de transporte de testemunhas, seu legislador estatuiu:

a) "art. 250 - Se qualquer testemunha tiver de ausentar-se ou se, por motivo de idade ou de molestia grave, for de receiar que ao tempo da prova já não exista, poderá ser inquirida antecipadamente, com prévia notificação dos interessados, entregando-se o depoimento ao requerente nas quarenta e oito horas seguintes, para dele servir-se como e quando entender".

b) "art. 213 - A prova que houver de produzir-se fora da jurisdição do juiz, será feita por precatória ou rogatória, conforme o caso, na forma dos arts. 6 a 13".

Esse artigo 213 compreende a produção de quaisquer meios de prova, porque está redigido de fórma que não deixa dúvidas a respeito dessa generalidade de compreensão, como está tambem subordinado à rubrica do capítulo intitulado "Das provas em geral". E ele, a nosso ver, declaração legal de que o Código de Processo Civil permite a produção da prova testemunhal, como de qualquer outra prova, no juizo deprecado.

A permissão, porém, (e aquí parece residir a maior dificuldade na matéria) não está subordinada expressamente a nenhuma regra concreta de que decorram direitos processuais dos interesados a obterem a produção dessa prova, pois ela ha de ser admitida apenas quando "houver de produzir-se fora da jurisdição do juiz" da causa. É o juiz que, na falta de uma regra a ele imposta, segundo a qual deva dar ou negar a precatória para tal fim requerida, julgará da necessidade ou da conveniência de admití-la.

Assim é exatamente porque, segundo o artigo 112, "o juiz dirigirá o processo por fórma que assegure à causa anda- 
mento rápido, sem prejuizo da defesa dos interessados"; e porque, segundo o artigo 117, a "requerimento ou "ex-officio", o juiz poderá, por despacho motivado, ordenar as diligências necessárias à instrução do processo e indeferir as inuteis em relação a seu objeto, ou requeridas com propositos manifestamente protelatórios".

Tais princípios são reflexo do poder inquisitivo do juiz civil e refletem a orientação nova do legislador, no sentido de operar a penalização, por assim dizer, do processo civil. Se, entretanto, esse mesmo juiz, com esse mesmo poder inquisitivo, entender que a prova produtivel por precatória é indispensavel ao esclarecimento da verdade, tomará na devida conta o que dispõem razoavelmente, pois, os artigos 214 e 215:

“A precatória e a rogatória não terão efeito suspensivo, salvo se, requeridas antes do despacho saneador, a decisão depender principalmente da prova pretendida";

“A precatória e a rogatória não devolvidas em tempo e as concedidas sem suspensão do feito serão juntas aos autos até o julgamento final na superior instância".

\section{Em resumo}

8. A oralidade processual existe no Brasil ha mais de cem anos, em matéria criminal. Consiste ela na concentração do processo na audiência de julgamento, observada a mesma ordem racional de atos que adota o atual Código de Processo Civil. Da mesma sorte que no crime, a instransportabilidade de certos meios de prova para o lugar da audiência e a inadiabilidade de produção de certas provas acarretam, no civel, uma atividade preparatória de produção de provas, cujos resultados escritos valem no julgamento da causa. 